\title{
Potential of xenon to induce or to protect against neuroapoptosis in the developing mouse brain
}

\author{
[Le potentiel du xénon pour induire ou protéger contre la neuroapoptose dans le \\ cerveau en développement de la souris]
}

Davide Cattano MD phD,$\uparrow \$$ Peter Williamson mBBS BSc, $\ddagger$ Kimiko Fukui MD, $†$ Michael Avidan MD, $†$ Alex S. Evers $\mathrm{MD}, \dagger$ John $\mathrm{W}$. Olney MD, ${ }^{*}$ Chainllie Young MD PhD*

Purpose: Drugs that suppress neuronal activity, including all general anesthetics that have been tested thus far (ketamine, midazolam, isoflurane, propofol, and a cocktail of midazolam, nitrous oxide and isoflurane), trigger neuroapoptosis in the developing rodent brain. Combinations of nitrous oxide and isoflurane, or ketamine and propofol, cause more severe neuroapoptosis than any single agent by itself, which suggests a positive correlation between increased levels of anesthesia and increased severity of neuroapoptosis. In contrast, there is evidence that the rare gas, xenon, which has anesthetic properties, protects against isoflurane-induced neuroapoptosis in the infant rat brain, while not inducing neuroapoptosis by itself. The present study was undertaken to evaluate the potential of xenon to induce neuroapoptosis or to protect against neuroapoptosis induced by isoflurane in the infant mouse brain.

Methods: Seven-day-old C57BL/6 mice were exposed to one of four conditions: air (control); $0.75 \%$ isoflurane; $70 \%$ xenon; or $0.75 \%$ isoflurane $+70 \%$ xenon for four hours. For histopathological evaluation of the brains, all pups were euthanized two hours later using activated caspase- 3 immunohistochemical staining to detect apoptotic neurons. Under each condition, quantitative assessment of the number of apoptotic neurons in the cerebral cortex (CC) and in the caudate/putamen (C/P) was performed by unbiased stereology.

Results: The combination of xenon + isoflurane produced a deeper level of anesthesia than either agent alone. Both xenon alone $(P<0.003$ in $C C ; P<0.02$ in $C / P)$ and isoflurane alone $(P<0.001$ in both $C C$ and $C / P)$ induced a significant increase in neuroapoptosis compared to controls. The neuroapoptotic response to isoflurane was substantially more robust than the response to xenon. When xenon was administered together with isoflurane, the apoptotic response was reduced to a level lower than that for isoflurane alone $(P<0.01$ in $\mathrm{CP}$; marginally non-significant in CC).

Conclusions: We conclude that xenon, in the infant mouse brain, has paradoxical properties. It triggers neuroapoptosis, and when combined with isoflurane, it increases the depth of anesthesia, and retains its own apoptogenic activity. However, it suppresses, rather than augments, isoflurane's apoptogenic activity.

CAN J ANESTH $2008 / 55: 7 /$ pp 429-436

Objectif: Les médicaments supprimant l'activité neuronale, y compris tous les anesthésiants généraux testés jusqu'à présent (kétamine, midazolam, isoflurane, propofol, et un cocktail de midazolam, de protoxyde d'azote et d'isoflurane) déclenchent la neuroapoptose dans le cerveau en développement des rongeurs. Des combinaisons de protoxyde d'azote de d'isoflurane, ou de kétamine et de propofol, provoquent une neuroapoptose plus grave que n'importe quel agent administré seul, ce qui suggère une corrélation positive entre des niveaux plus élevés d'anesthésie et une neuroapoptose plus grave. En revanche, il existe des données soutenant que le xénon, un gaz rare qui présente des propriétés anesthésiques, protège de la neuroapoptose induite par l'isoflurane dans le cerveau de rongeurs nourrissons, alors que seul, il n'induit

From the Departments of Psychiatry, ${ }^{*}$ and Anesthesiology, $†$ Washington University School of Medicine, St. Louis, Missouri, USA; the Department of Anaesthetics, Intensive Care \& Pain Medicine, $\ddagger$ Imperial College London, Chelsea \& Westminster Hospital, London, United Kingdom; and the Departments of Anesthesiology Surgery, $\$$ School of Medicine, University of Pisa, Pisa, Italy. Address correspondence to: Dr. John W. Olney, Department of Psychiatry, Washington University School of Medicine, 660 South Euclid,

St. Louis, MO 63110, USA. Phone: 314-362-2479; Fax: 314-747-0346; E-mail: olneyj@psychiatry.wustl.edu

Financial support: Supported in part by NIH grant HD 37100 and a grant from the Department of Anesthesiology, Washington University.

Accepted for publication March 4, 2008.

Revision accepted March 28, 2008.

This article is accompanied by an editorial. Please see Can J Anesth 2008; 55: 403-7. 
pas de neuroapoptose. Cette étude a été menée dans le but d'évaluer le potentiel du xénon pour induire la neuroapoptose ou de protéger contre la neuroapoptose provoquée par l'isoflurance dans le cerveau de rongeurs nourrissons.

Méthode : Des souris C57BL/6 de sept jours ont été exposées à un de quatre états : air (témoin) ; 0,75\% isoflurane ; $70 \%$ xénon ; ou $0,75 \%$ isoflurane $+70 \%$ xénon pendant quatre heures. Afin de réaliser une évaluation histopathologique du cerveau, tous les petits ont été euthanasiés deux heures plus tard à l'aide d'une technique de coloration immunohistochimique de caspase-3 activée pour permettre de détecter les neurones apoptotiques. Dans chaque état, une évaluation quantitative du nombre de neurones apoptotiques dans le cortex cérébral (CC) et dans le noyau caudé / putamen $(C / P)$ a été réalisée par stéréologie non biaisée.

Résultats : La combinaison de xénon + isoflurane a provoqué un niveau d'anesthésie plus profond que lorsque les agents ont été administrés seuls. Le xénon seul $(P<0,003$ dans $C C ; P<0,02$ dans $C / P)$ et l'isoflurane seul $(P<0,00$ l dans le $C C$ et le $C / P)$ ont provoqué une augmentation significative de neuroapoptose par rapport au groupe témoin. La réaction neuroapoptotique à l'isoflurane était considérablement plus puissante que la réaction au xénon. Lorsque le xénon a été administré avec l'isoflurane, la réaction apoptotique a diminué à un niveau plus bas que celui de l'isoflurane seul ( $P<0,0$ I dans $C P$; marginalement non significatif dans $C C)$.

Conclusion : Nous concluons que le xénon, dans le cerveau de rongeurs nourrissons, possède des propriétés paradoxales. II déclenche la neuroapoptose et, lorsqu'il est combiné à l'isoflurane, approfondit l'anesthésie, et retient sa propre activié apoptogène. Toutefois il supprime plutôt qu'augmente l'activité apoptogène de l'isoflurane.

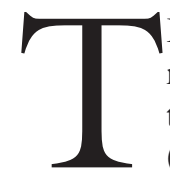

RANSIENT exposure of infant rats or mice to several classes of drugs, including those that block N-methyl-D-aspartic acid (NMDA) glutamate receptors, those that activate gamma aminobutyric acid $(\mathrm{GABA})$, receptors, and ethanol (which has both NMDA antagonist and GABAmimetic properties), triggers widespread neurodegeneration in the developing brain. ${ }^{1-5}$ The window of vulnerability to these agents coincides with the developmental period of synaptogenesis, also known as the brain growth spurt period. In mice and rats, this period occurs primarily in the early postnatal period, but in humans, it extends from about midgestation to several years after birth. ${ }^{6}$

The cell death process triggered by these drugs has been studied histologically and has been found, at both light and electron microscopic levels, to have classical morphological characteristics of apoptosis. ${ }^{7,8}$

Studies examining gene-regulated biochemical pathways have revealed that the cell death process involves translocation of Bax protein to mitochondrial membranes. It disrupts membrane permeability allowing extramitochondrial leakage of cytochrome $\mathrm{c}$, followed by a sequence of changes culminating in activation of caspase-3. ${ }^{9}$ Commitment to cell death occurs prior to the caspase- 3 activation (C3A) step; ${ }^{10}$ therefore, immunohistochemical detection of neurons, positive for $\mathrm{C} 3 \mathrm{~A}$, provides a reliable means of mapping and of quantifying dying cells that have already progressed beyond the point of cell death commitment.

The above findings have relevance in a public health context, because there are many agents in the human environment that have NMDA antagonist or GABAmimetic properties. Such agents include drugs that may be abused by pregnant mothers [ethanol, phencyclidine (angel dust), ketamine (Special K), nitrous oxide (laughing gas), barbiturates, and benzodiazepines] and many drugs used worldwide, in obstetric and pediatric medicine, as anticonvulsants, sedatives, or anesthetics. Particularly problematic is evidence that most, if not all, general anesthetics have either NMDA antagonist or GABAmimetic properties. ${ }^{11-13}$ In pediatric anesthesia, drugs in both of these categories are often administered in combination, which signifies that patients are being exposed to the same, or a very similar, combination of mechanisms by which ethanol damages the human fetal brain.

In a recent study, infant rats were exposed, for six hours, to a clinically relevant cocktail of anesthetic drugs (midazolam, nitrous oxide, and isoflurane) having both NMDA antagonist and GABAmimetic properties. The outcome was an extensive pattern of neuroapoptosis affecting many brain regions and subsequent cognitive deficits that were particularly severe in pre-adolescent rats and were still detectable in adulthood. ${ }^{5}$ More recently, it was reported ${ }^{14}$ that combined administration of ketamine, with either propofol or thiopental, caused more neuroapoptosis and subsequent cognitive deficits than any single agent by itself.

In another recent study, ${ }^{15}$ we examined the potential of the NMDA antagonist, ketamine, and the GABAmimetic, midazolam, to trigger neuroapoptosis, when administered individually, or in combination, to infant mice. Each drug was administered as a single subcutaneous injection at a subanesthetic dose. We found that either agent, at a subanesthetic dose, triggered a statistically significant apoptosis response in the caudate nucleus and in the cerebral cortex (CC) of the postnatal day seven (P7) infant mouse. When the two agents were administered in combination, an additive response was observed. In a separate study, we have determined that propofol, at sub-anesthetic doses, 
also triggers a significant neuroapoptosis response in the infant mouse brain. ${ }^{16}$

Isoflurane, a halogenated volatile anesthetic, is frequently used in pediatric general anesthesia and is especially useful for maintaining a surgical plane of anesthesia for a period of many hours. Isoflurane's anesthetic action is thought to be mediated by multiple mechanisms, including actions at $\mathrm{GABA}_{\mathrm{A}}$, glycine and glutamate receptors, and at two-poredomain, potassium channels. ${ }^{17-20}$ Isoflurane also exerts a depolarizing action on neural mitochondria. ${ }^{21}$ The minimum alveolar concentration of isoflurane, for maintaining an anesthetic state in the infant mouse, is $2.3 \% .^{22}$ Recently, we demonstrated ${ }^{23}$ that exposure to sub-minimum alveolar concentrations of isoflurane for one or more hours, is sufficient to induce neuroapoptosis in the infant mouse brain.

Xenon, a rare gas, has NMDA antagonist proper$\operatorname{ties}^{24}$ and is the only known NMDA antagonist gas that can provide a surgical plane of anesthesia at normobaric pressure. Reportedly, xenon is safe for anesthetic use in human neonates ${ }^{25}$ and does not cause teratogenic effects in infant rats, as has been reported following isoflurane anesthesia. ${ }^{26}$ Very recently, Ma et al. ${ }^{27}$ reported that xenon, when administered together with isoflurane, reduced the neuroapoptotic response to isoflurane, and xenon, by itself, was not neurotoxic. Thus, xenon appears to be an exceptionally promising candidate for pediatric anesthesia, provided that all of these favourable properties can be corroborated. Accordingly, the present study was undertaken to evaluate the potential of xenon to induce neuroapoptosis or to protect against neuroapoptosis induced by isoflurane in the infant mouse brain.

\section{Materials and methods Animals and procedures}

All animal procedures were conducted in accordance with guidelines developed by the National Academy of Science and were approved by the Washington University Animal Care Committee. Infant C57BL6 mice were used in all experiments. Previously, we have observed that at P5 to P7, when C57BL6 mice are at an average body weight of about 2.5 to $3.5 \mathrm{~g}$, they are maximally sensitive to drug-induced neuroapoptosis. However, at P7 there is a rapid shift in sensitivity indicating that as they become only slightly older, they become less sensitive to this neurotoxic effect. Therefore, for the present study, we used P5 to P7 mice from litters that had a mean body weight $\leq 3.5 \mathrm{~g}$. The study was undertaken in two phases.

In the phase 1 experiments, we tested the ability of xenon by itself $(70 \%$ xenon, remainder oxygen; exposure time $=$ four hours) to induce neuroapoptosis. Control animals were exposed to all of the same conditions, except they breathed room air instead of xenon. Previously, we have observed that there is considerable litter variability in the rate of apoptosis spontaneously occurring in infant mice, and the spontaneous rate co-varies with their sensitivity to drug-induced neuroapoptosis (litters that have more spontaneous apoptosis are correspondingly more sensitive to drug-induced apoptosis). Therefore, an equal number of pups was assigned from each litter to the experimental and control conditions. In addition, although we have observed in prior studies that male and female pups are equally sensitive to drug-induced neuroapoptosis, we assigned, as nearly as possible, an equal number of male and female animals to the control and experimental conditions.

In the phase 2 experiments, we compared the neuroapoptogenic properties of two anesthetic protocols - isoflurane alone and isoflurane + xenon. The duration of anesthesia in all experiments was four hours. The isoflurane concentration was $0.75 \%$ in room air (for isoflurane alone) or $0.75 \%$ isoflurane in $70 \%$ xenon, remainder oxygen, for the combined drug experiments. Control animals were exposed to all of the same conditions, except they breathed room air instead of a mixture containing anesthetic gases. Pups from each litter were distributed equally among the treatment conditions (room air, isoflurane alone, isoflurane + xenon), in the same manner as described above.

\section{Anesthesia exposure conditions}

The duration of exposure in all experiments was four hours. Anesthetic exposure occurred in a flow-through chamber in which the gases entered through one portal and exited through another on the opposite side. Since xenon is in scarce supply, we used a closed recirculation system, allowing it to be recycled through the chamber. The gas flow was facilitated by a small pump attached to the circuit. The flow rate of the gases was 3-4 $\mathrm{L} \cdot \mathrm{min}^{-1}$. Xenon was administered from a tank containing $70 \%$ xenon and $30 \%$ oxygen. To provide identical conditions for all experiments, exposure to each gas or gas combination occurred in a chamber of the same size, and an identical closed recirculation system was used. For the controls, the gas circulated through the system was room air. For xenon alone, the gas mixture was $70 \%$ xenon, 30\% oxygen. For isoflurane alone, the gas mixture was isoflurane $0.75 \%$ vaporized in room air, and for xenon + isoflurane, it was isoflurane $0.75 \%$, xenon $70 \%$, remainder oxygen. The pups were maintained at a constant ambient 
temperature $\left(30^{\circ} \mathrm{C}\right)$ by placing the gas chambers in a water bath. Drierite and soda lime, wrapped in a 4 $\times 4$ swab, were placed in the chamber to absorb $\mathrm{CO}_{2}$ and moisture. The concentrations of oxygen, xenon, and isoflurane were monitored by an in-line gas analyzer (Datex Cardiocap II, Datex-Ohmedi, Madison, WI, USA) and were regulated to maintain concentrations stated above. After four hours of anesthesia (or exposure to room air), the pups were removed from the chamber and were allowed to recover in a warm cage $\left(30^{\circ} \mathrm{C}\right)$ simulating the maternal cage, but in the absence of the mother.

\section{Histopathology}

Two hours after termination of anesthesia, the pups were deeply anesthetized with pentobarbital and perfused with fixative (4\% paraformaldehyde in Tris buffer) through the left cardiac ventricle and the ascending aorta. The brains were removed from the skulls and were immersed in the perfusion fixative overnight in the refrigerator. Next, the brains were bisected sagittally; sectioned serially, by vibratome in the sagittal plane; and stained immunohistochemically for C3A, by methods previously described ${ }^{8}$ Briefly, vibratome sections $(50 \mu \mathrm{m}$ thick) were washed in $0.01 \mathrm{M}$ phosphate-buffered, saline (PBS) solution and were quenched for ten minutes in a solution of methanol containing 3\% hydrogen peroxide. After that, they were incubated for one hour in blocking solution ( $2 \%$ BSA $/ 0.2 \%$ milk/0.1 \% Triton X-100 in PBS), followed by incubation overnight in rabbit anti-active caspase- 3 antiserum (D175, Cell Signaling Technology, Beverly, MA, USA), diluted 1:1000 in blocking solution. Following incubation with D175 primary antibody, the sections were incubated for one hour in secondary antibody (goat anti-rabbit 1:200 in blocking solution). Next, the sections were reacted for one hour in the dark with $\mathrm{ABC}$ reagents (standard Vectastain ABC Elite Kit, Vector Labs, Burlingame, CA, USA). The sections were then washed three times with PBS and incubated with VIP reagent (Vector VIP substrate kit for peroxidase, Vector Labs, Burlingame, CA, USA) to develop a purple colour.

\section{Quantitative cell counts}

For quantitative counts of apoptotic neurons, every eighth section was chosen in an unbiased manner, with systematic random sampling according to the principle of stereology. ${ }^{28}$ This process facilitated sampling eight to ten sections from half of each brain. These sections were imaged and were quantitatively evaluated with the help of a stereology system consisting of the following components: a Stereo Investigator (MicroBrightField, Inc, Colchester, VT, USA) on a Pentium III PC; connected to a Prior Optiscan motorized stage (ES103 XYZ system, Prior Scientific Inc, Rockland, MA, USA) mounted on a Nikon Labophot-2 microscope. The boundaries of the brain regions of interest $[(\mathrm{CC})$ and caudate-putamen $(\mathrm{C} / \mathrm{P})]$ were traced into the $\mathrm{PC}$, and stereo investigator calculated the area in each section from the tracings. In the cortex, the majority of AC3-positive profiles were in layer II; but counts were performed across the entire extent of the CC. In the $\mathrm{C} / \mathrm{P}, \mathrm{AC} 3$-positive profiles were present in scattered or loosely clustered distribution throughout the dorsal and ventral portions. Caspase- 3 positive neurons with visible dendrites or axons were all counted. For those profiles without obvious dendritic processes, only those with a size larger than $8 \mu \mathrm{m}$ were counted. The population estimator function of stereo investigator was used to mark each profile while it was counted, to ensure that no profile would be missed or counted twice. To obtain an estimate of the total number of AC3-positive profiles in the reference brain region $(\mathrm{CC}$ or $\mathrm{C} / \mathrm{P})$, we summed the counts from all sections containing that brain region. Since the counts were made on every eighth section, we multiplied the sum of the counts by 8 . The counts were performed by an experienced histopathologist (C.Y.) who was blind to the treatment condition.

\section{Statistical methods}

Prism 4.0b (GraphPad Software Inc., San Diego, CA, USA) was used for all statistical analyses. All data are shown as mean \pm standard deviation. For analysis of the data from the first experiment, we used the unpaired $t$ test with Welch correction. For analysis of the second experiment which involved multiple comparisons, we used a one-way analysis of variance (ANOVA) with Student-Newman-Keuls multiple comparisons test and log transformation of the data, where appropriate.

\section{Results}

Exposure of infant mice to xenon alone, or isoflurane alone, for four hours triggered a neuroapoptosis response, as detected by AC3 immunohistochemistry in both the $\mathrm{CC}$ and $\mathrm{C} / \mathrm{P}$. Figure 1 illustrates the histological appearance of the AC3 positive staining following isoflurane compared to the control condition.

The mean magnitude of the neuroapoptosis response to xenon $(n=10)$ in the $\mathrm{CC}$ and in the $\mathrm{C} / \mathrm{P}$, respectively, was 2.0 and 2.4 times greater than the rate of spontaneous neuroapoptosis in litter-matched controls $(n=9)$ exposed to room air (Figure 2$)(P<0.003$ and 

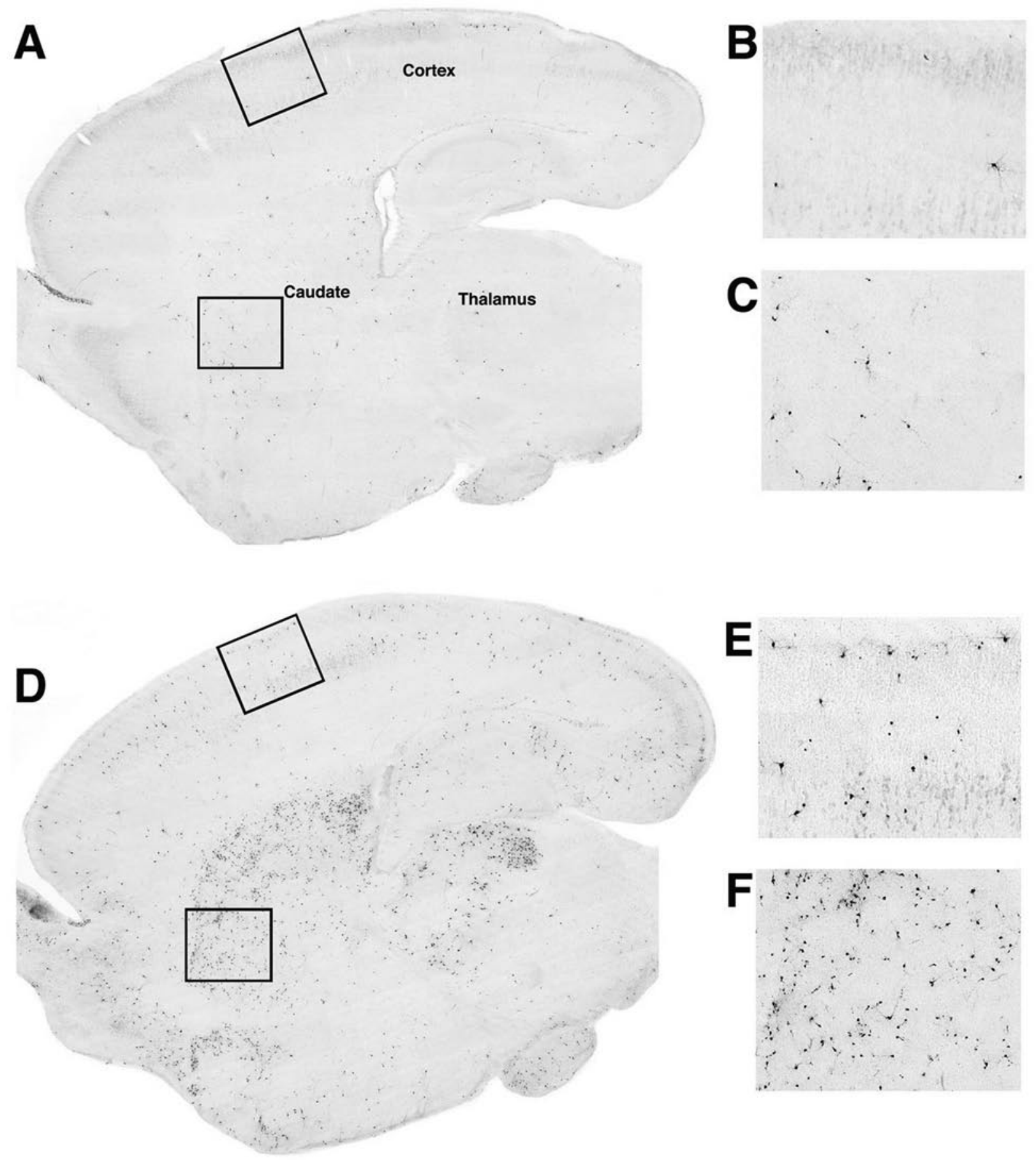

FIGURE 1 Panels A and D are light microscopic sagittal sections from the brain of a saline control mouse (A) and an isoflurane-exposed mouse (D). Both sections are stained immunohistochemically for activated caspase-3 (AC3). Panels B, C, E, and F are magnified views from the caudate and the cerebral cortex (boxed regions) in A and D, respectively. The control brain (A, B, C) has a sparse pattern of AC3 staining, which represents the rate of spontaneous neuroapoptosis in the normal P5-7 mouse brain. A much higher density of AC3 positive profiles is present in the isoflurance-exposed brain $(\mathrm{D}, \mathrm{E}$, and $\mathrm{F})$. 

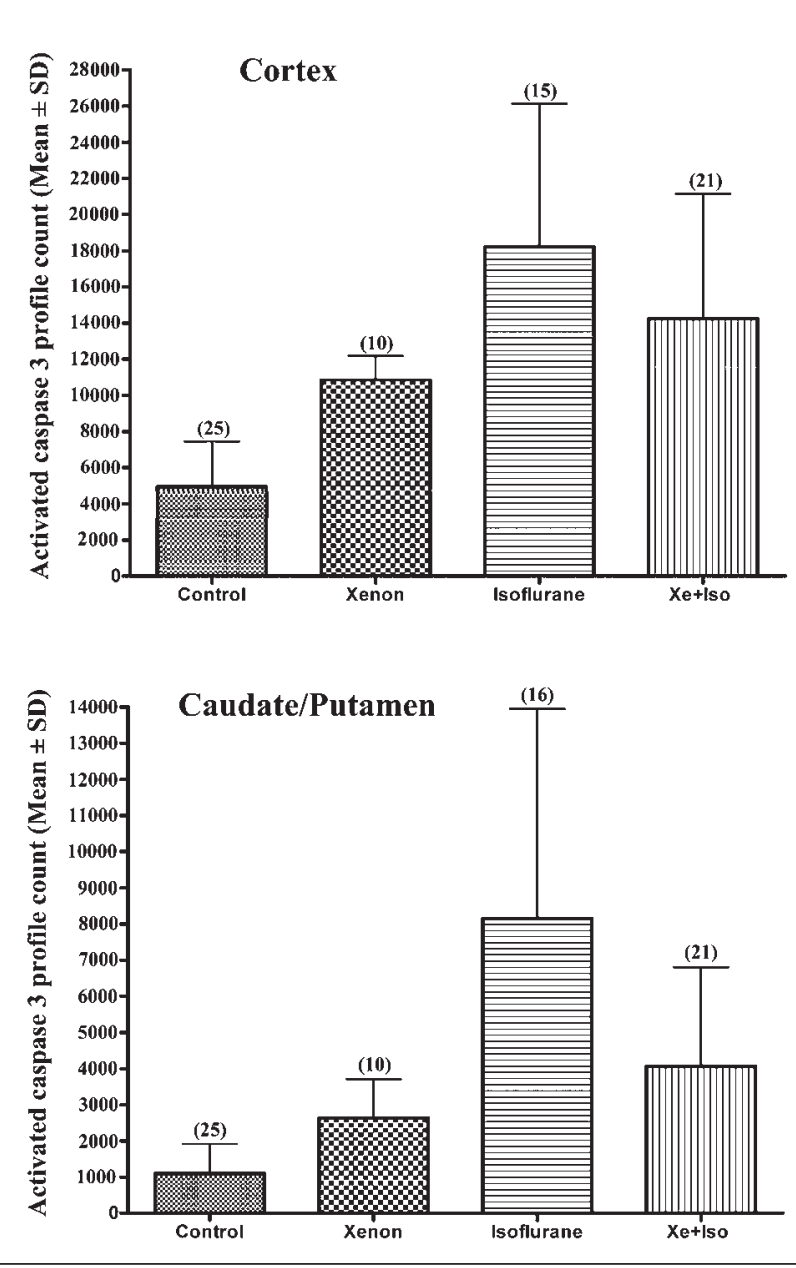

FIGURE 2 Counts of activated caspase-3 (AC3)-positive profiles in the caudate-putamen and in the cerebral cortex of mouse pups exposed for four hours to room air, xenon, isoflurane, or xenon + isoflurane. The data were gathered in two separate experiments; however, for illustration purposes they are incorporated into a single histogram for each brain region studied. For statistical analyses, the data for each treatment group were compared to its own litter-mate, control group. The values plotted are means \pm standard deviation. The number of animals per experimental condition is given in parentheses. The mean numbers of AC3positive profiles is significantly increased in both brain regions of the xenon-exposed pups compared to litter mate controls $(P<0.003$ for cerebral cortex and $P<0.02$ for caudate-putamen $)$. Isoflurane significantly increased the rate of neuroapoptosis compared to litter-mate controls in both brain regions $(P<0.001)$. Adding xenon significantly reduced the apoptosis response to isoflurane in the caudate-putamen $(P<0.01)$ and, to a marginally non-significant degree, in the cerebral cortex.

0.02 for $\mathrm{CC}$ and $\mathrm{C} / \mathrm{P}$, respectively; unpaired $t$ test with Welch correction).

In additional litters of mice, we examined the effect of isoflurane alone $(n \geq 15)$ or isoflurane + xenon $(n=21)$ compared to room air controls $(n=16)$.
One-way ANOVA revealed a main effect of drug exposure for $\mathrm{CC}[\mathrm{F}(2,49)=31.180, P=0.0001]$ and for $\mathrm{C} / \mathrm{P}[\mathrm{F}(2,50)=27.216, P=0.0001]$. Isoflurane alone induced a robust neuroapoptotic response in the $\mathrm{CC}$ and in the $\mathrm{C} / \mathrm{P}$ that was 4.0 and 6.7 times greater, respectively, than the rate of spontaneous neuroapoptosis in litter-matched controls $(P<0.001$ for CC and for C/P; Student-Newman-Keuls multiple comparisons test). Combining xenon with isoflurane did not augment the neuroapoptotic response, but rather diminished it compared to the response to isoflurane alone. By Student-Newman-Keuls multiple comparisons test, this mitigating effect was statistically significant in the $\mathrm{C} / \mathrm{P}(P<0.01)$, but was marginally non-significant in the CC (Figure 2). In both regions, the neuroapoptosis response, following exposure to the combination, was reduced to a level that was not significantly different from the level induced by xenon alone.

\section{Discussion}

Our findings confirm a major feature of the observations reported recently by $\mathrm{Ma}$ et al. ${ }^{27}$ specifically, xenon protects against isoflurane-induced neuroapoptosis. The protective action was statistically significant in the $\mathrm{C} / \mathrm{P}$ but marginally non-significant in the CC. However, assessing the protective action, solely in statistical terms, and focusing on the amount by which the combined treatment reduced the response below the isoflurane-alone level may not capture the full biological significance of the protective effect. It is important to recognize that the expectation, based on the bulk of previous evidence, ${ }^{5,14,15,27}$ is that combining an NMDA antagonist (e.g., nitrous oxide or ketamine) with a GABAmimetic agent (e.g., isoflurane, midazolam, or propofol) would result in an additive or potentiated neuroapoptosis reaction. In practical terms, the issue is not whether xenon significantly reduced isoflurane's neurotoxicity compared to isoflurane alone, but by how much xenon reduced it, compared to the potentiated levels expected for a combination of an NMDA antagonist (xenon) and a GABAmimetic (isoflurane). Viewing it from this perspective, the degree of protection would be both biologically meaningful and statistically significant.

Xenon's protective action is of considerable interest, in that isoflurane and its structural analogs are a major ingredient of many anesthetic protocols commonly used worldwide in pediatric and obstetric anesthesia. If another agent that is capable of providing general anesthesia can replace the halogenated family of volatile anesthetics in pediatric anesthesia, or can be used in conjunction with them to achieve optimal levels of 
anesthesia while minimizing neurotoxic side effects, this is a lead well worth pursuing. Xenon is an effective general anesthetic, when applied at $70 \%$ of one atmosphere in humans ${ }^{24}$, and has been used safely for anesthetic or radiological applications in human neonates. ${ }^{25}$ Additional advantages in human anesthesia include; ease of administration, rapid onset of action, and rapid recovery. ${ }^{29,30}$ Since xenon is exceedingly scarce, difficult to extract in large quantities, and, consequently, very costly, progress in making it commercially available as a general anesthetic has been impeded.

Setting aside the issue of xenon's limited availability, the finding that xenon can prevent much of isoflurane's neurotoxic effects on the developing brain, while delivering a surgical level of anesthesia, is of theoretical as well as of practical interest. We have postulated, based on the following observations, that the deeper the level and the longer the duration of anesthesia, the greater will be the neuroapoptotic response. First, we identified that all GABAmimetic agents and all NMDA antagonists tested thus far, have been found to have neuroapoptogenic properties. Secondly, we recognize that the common denominator of these two classes of agents is that they suppress neuronal activity. Furthermore, we acknowledge that suppression of neuronal activity is a necessary component of general anesthesia. This prediction is consistent with our finding that a triple-ingredient anesthetic cocktail caused a relatively severe apoptotic response in infant rats, ${ }^{5}$ and that a combination of midazolam and ketamine caused a greater apoptotic response than either agent alone. ${ }^{15}$ Moreover, Fredriksson et al. ${ }^{14}$ recently reported that the neuroapoptosis response is potentiated by combining ketamine with either propofol or thiopental. The present findings signify that, while this prediction may be true for some anesthetic drug combinations, it is not true for all. By combining xenon and isoflurane, it is possible to deepen the level of anesthesia (duration remaining the same) while diminishing the amount of neurotoxicity. Thus, the amount of anesthesia and the amount of neuroapoptosis are independent variables that co-vary in locked unison only some of the time. An important implication is that a thorough testing of all possible anesthetic drug combinations should result in the identification of some protocols that are safer than others.

The fact that xenon can partially counteract isoflurane's neurotoxicity suggests that there may be other agents, either anesthetic or non-anesthetic, which, by the same or by a similar mechanism, can provide additional protection against anesthesia-induced neuroapoptosis.
On a less optimistic note, our findings do not confirm the Ma et al. ${ }^{27}$ conclusion that xenon is totally free from neuroapoptogenic activity. Although the amount of neuroapoptosis induced by xenon was substantially less than that induced by isoflurane, xenon did induce a significant increase in neuroapoptosis in the $\mathrm{CC}$ and $\mathrm{C} / \mathrm{P}$. Therefore, whether administered as a stand-alone anesthetic or in combination with isoflurane, our findings suggest that xenon may exert at least a low level of unopposed neuroapoptogenic activity. Moreover, the value of xenon as a neuroprotective agent will depend, in part, on whether it can be shown in future studies to protect against the neurotoxicity of other anesthetic drugs as well as isoflurane.

From a mechanistic standpoint, xenon presents an enigma. How can it cause neuroapoptosis by itself, but prevent neuroapoptosis induced by isoflurane? A likely explanation would be that xenon triggers apoptosis through an intracellular signalling pathway separate from the one through which isoflurane triggers neuroapoptosis, and its protective mechanism is operative in the isoflurane toxicity pathway, but not in the xenon toxicity pathway. Presumably, the NMDA antagonist property of xenon plays a role in mediating its apoptogenic activity. We have found ${ }^{31}$ in the in vivo, infant mouse that ethanol, an apoptogenic drug that also has NMDA antagonist properties, causes a rapid (within $<30 \mathrm{~min}$ ) decrease in the phosphorylated isoforms of extracellular signalregulated protein kinase (ERK) and Akt, both of which are key proteins in signalling pathways that contribute to the regulation of cell survival. Thus, the ERK and Akt pathways are promising targets for future research aimed at clarifying the apoptogenic and/or the neuroprotective properties of xenon.

\section{Acknowledgement}

We are thankful to Air Products Chemical Industries, Allentown, PA, for supplying the xenon.

\section{References}

l Ikonomidou C, Bosch F, Miksa M, et al. Blockade of NMDA receptors and apoptotic neurodegeneration in the developing brain. Science 1999; 283: 70-4.

2 Ikonomidou C, Bittigau P, Ishimaru MJ, et al. Ethanolinduced apoptotic neurodegeneration and fetal alcohol syndrome. Science 2000; 287: 1056-60.

3 Olney JW, Tenkova T, Dikranian K, Qin YQ Labruyere $J$, Ikonomidou C. Ethanol-induced apoptotic neurodegeneration in the developing C57BL/6 mouse brain. Dev Brain Res 2002; 133: 115-26.

4 Bittigau P, Sifringer M, Genz K, et al. Antiepileptic drugs and apoptotic neurodegeneration in the develop- 
ing brain. Proc Natl Acad Sci USA 2002: 99: 15089-94.

5 Jevtovic-Todorovic V, Hartman RE, Izumi $\Upsilon$, et al. Early exposure to common anesthetic agents causes widespread neurodegeneration in the developing rat brain and persistent learning deficits. J Neurosci 2003; 23: 876-82.

6 Dobbing J, Sands J. Comparative aspects of the brain growth spurt. Early Hum Dev 1979; 3: 79-83.

7 Dikranian K, Ishimaru MJ, Tenkova T, et al. Apoptosis in the in vivo mammalian forebrain. Neurobiol Dis 2001; 8: 359-79.

8 Olney JW, Tenkova T, Dikranian K, et al. Ethanolinduced caspase- 3 activation in the in vivo developing mouse brain. Neurobiol Dis 2002; 9: 205-19.

9 Young C, Klocke BJ, Tenkova T, et al. Ethanol-induced neuronal apoptosis in vivo requires BAX in the developing mouse brain. Cell Death Differ 2003; 10: 1148-55.

10 Young C, Roth KA, Klocke BJ, et al. Role of caspase-3 in ethanol-induced developmental neurodegeneration. Neurobiol Dis 2005; 20: 608-14.

11 Franks NP, Lieb WR. Molecular and cellular mechanisms of general anaesthesia. Nature 1994; 367: 607-14.

12 Jevtovic-Todorovic V, Todorovic SM, Mennerick S, et al. Nitrous oxide (laughing gas) is an NMDA antagonist, neuroprotectant and neurotoxin. Nat Med 1998; 4: 460-3.

13 Jenkins A, Greenblatt EP, Faulkner HJ, et al. Evidence for a common binding cavity for three general anesthetics within the GABAA receptor. J Neurosci 2001; 21: RC136.

14 Fredriksson A, Ponten E, Gordh T, Eriksson P. Neonatal exposure to a combination of $\mathrm{N}$-methyl-D-aspartate and gamma-aminobutyric acid type A receptor anesthetic agents potentiates apoptotic neurodegeneration and persistent behavioral deficits. Anesthesiology 2007; 107: 427-36.

15 Young C, Jevtovic-Todorovic V, Qin YO, et al. Potential of ketamine and midazolam, individually or in combination, to induce apoptotic neurodegeneration in the infant mouse brain. Br J Pharmacol 2005; 146: 189-97.

16 Cattano D, Young C, Straiko M, Olney JW. Subanesthetic doses of propofol induce neuroapoptosis in the infant mouse brain. Anesth Analg 2008 (in press).

17 Winegar BD, Yost CS. Volatile anesthetics directly activate baseline $S \mathrm{~K}+$ channels in aplysia neurons. Brain Res 1998; 807: 255-62.

18 Talley EM, Bayliss DA. Modulation of TASK-1 (Kenk3) and TASK-3 (Kcnk9) potassium channels: volatile anesthetics and neurotransmitters share a molecular site of action. J Biol Chem 2002; 277: 17733-42.
19 Grasshoff C, Rudolph U, Antkowiak B. Molecular and systemic mechanisms of general anaesthesia: the 'multisite and multiple mechanisms' concept. Curr Opin Anaesthesiol 2005; 18: 386-91.

20 Franks NP. Molecular targets underlying general anesthesia. Br J Pharmacol 2006; 147: Suppl 1: S72-81.

21 Bains R, Moe MC, Larsen GA, Berg-Johnsen J, Vinje $M L$. Volatile anaesthetics depolarize neural mitochondria by inhibition of the electron transport chain. Acta Anaesthesiol Scand 2006; 50: 572-9.

22 Loepke AW, Mccann JC, Kurth C, Mcauliffe JJ. The physiologic effects of isoflurane anesthesia in neonatal mice. Anesth Analg 2006; 102: 75-80.

23 Johnson SA, Young C, Olney JW. Isoflurane-induced neuroapoptosis in the developing brain of nonhypoglycemic mice. J Neurosurg Anesthesiol 2008; 20: 21-8.

24 Franks NP, Dickinson R, De Sousa S, Hall AC, Lieb $W R$. How does xenon produce anaesthesia? Nature 1998; 396: 324 .

25 Jayasinghe D, Gill AB, Levene MI. CBF reactivity in hypotensive and normotensive preterm infants. Pediatr Res 2003; 54: 848-53.

26 Lane GA, Nahrwold ML, Tait AR, Taylor-Busch M, Cohen PJ, Beaudoin AR. Anesthetics as teratogens: nitrous oxide is fetotoxic, xenon is not. Science 1980; 210: 899-901.

27 Ma D, Williamson P, Januszewski A, et al. Xenon mitigates isoflurane-induced neuronal apoptosis in the developing rodent brain. Anesthesiology 2007; 106: $746-53$.

28 Gundersen HJ, Bendtsen TF, Korbo L, et al. Some new, simple and efficient stereological methods and their use in pathological research and diagnosis. APMIS 1988; 96: 379-94.

29 Goto T, Saito H, Shinkai M, Nakata $\Upsilon$, Ichinose F, Morita $S$. Xenon provides faster emergence from anesthesia than does nitrous oxide-sevoflurane or nitrous oxide-isoflurane. Anesthesiology 1997; 86: 1273-8.

30 Rossaint R, Reyle-Hahn M, Schulte Am Esch J, et al; Xenon Study Group. Multicenter randomized comparison of the efficacy and safety of xenon and isoflurane in patients undergoing elective surgery. Anesthesiology 2003; 98: 6-13.

31 Young C, Olney JW. Rapid suppression of ERK and Akt phosphorylation by ethanolinduced neuroapoptosis in infant mouse brain. Soc Neurosci 2006; 89:1/MM95 (abstract) 